International Journal of Current Advanced Research

ISSN: O: 2319-6475, ISSN: P: 2319 - 6505, Impact Factor: SJIF: 5.995

Available Online at www.journalijcar.org

Volume 6; Issue 3; March 2017; Page No. 2904-2906

DOI: http://dx.doi.org/10.24327/ijcar.2017.2906.0138

Research Article

\title{
AWARENESS AMONGST DENTAL STUDENTS ABOUT THE HARMFUL EFFECTS OF BEVERAGES
}

\author{
Mugilan MR* and Preetha S
}

Saveetha Dental College \& Hospitals Chennai-600 077

\begin{tabular}{l}
\hline A R T I C L E I N F O \\
\hline Article History: \\
Received $20^{\text {th }}$ December, 2016 \\
Received in revised form $24^{\text {th }}$ January, 2017 \\
Accepted $4^{\text {th }}$ February, 2017 \\
Published online $28^{\text {th }}$ March, 2017
\end{tabular}

Key words:

Harmful Effects, Beverages

\begin{abstract}
A B S T R A C T
Aim: To establish awareness amongst dental students about the harmfulness effects of beverages.

Background: Beverages are liquids specifically prepared for human consumption. It is also a part of culture of human society. Beverages including juice, soft drinks, and carbonated drinks, have some form of water in them; As water is essential for life, it has also been the carrier of many diseases. The over-consumption of sugar-sweetened soft drinks is associated with obesity type 2 diabetes, dental caries, and low nutrient levels. Sugar-sweetened" includes drinks that use high-fructose corn syrup, as well as those using sucrose caffeine is linked to anxiety and sleep disruption when consumed in excess.

Materials and methods: The questionnaire included the basic information like subjects, name, sex, age. All these questions were framed to understand in depth how the intake of beverages could affect our life style.

Result: In this study we came to know that only $58 \%$ of dental students out of 100 was aware about the harmful effects of beverages.

Conclusion: Most of the students are aware of harmful effects of beveragesbut stillthey do not restrain themselves from these habits.
\end{abstract}

Copyright $\odot 2017$ Mugilan MR and Preetha S. This is an open access article distributed under the Creative Commons Attribution License, which permits unrestricted use, distribution, and reproduction in any medium, provided the original work is properly cited.

\section{INTRODUCTION}

Beverage is a common name to us but many peoples of us don't know what is beverage? Any liquid that can quench the thirst are called beverage [1]. The word Beverage is used as a replacement for the word of drink in the restaurant, bars or in shops [1]. In many countries the word drink is used as the word beverage. Certainly in Ancient Egypt beer was a common beverage used. People drank it from large containers through straws (to avoid drinking debris floating in the drink) [2]. After the Romans conquered Britain brewing continued. In the Ancient Middle East wine was also a common beverage. Most common beverage drinks are carbonated drinks which are highly sugared drinks and are named to be cold beverages [3]. Hot beverages include coffee tea etc [4]. While the term "soft drink" is commonly used in product labeling and on restaurant menus, in many countries these drinks are more commonly referred to by regional names, including carbonatedbeverage, coke, fizzy drink, fizzy juice, cool drink, cold drink, lolly water, pop, seltzer, soda, soda pop, tonic, and mineral[5][6]. Soft drinkconsumption has become a highly visible and controversial public health and public policy issue [3].

*Corresponding author: Mugilan MR

Saveetha Dental College \& Hospitals Chennai-600 077
Soft drinks are viewed by many as a major contributor to obesity and related health problems and have consequently been targeted as a means to help curtail the rising prevalence of obesity, particularly among children. Soft drinks have been banned from schools in Britain and France, and in the United States, school systems as large as those in Los Angeles, Philadelphia, and Miami have banned or severely limited soft drink sales [7]. Many US states have considered statewide bans or limits on soft drink sales in schools, with California passing such legislation in 2005[8].These beverages lead to overweight and obesity including hypertension, cardiovascular diseases, diabetes etc.. so, this study aims to know the awareness about harmful effects of beverages in the present life style among dental students.

\section{MATERIALS AND METHODS}

The participants for the study included 100 students from Saveetha Dental College aged between 17-21 years. A questionnaire accessing the influence of beverages on many disorders faced by thisgenerations. This study was a questionnaire based study. The questionnaire was selfadministered. The questionnaire included the basic information like the subjects' name, age, sex. All these questionnaires were framed to understand in depth how the intake of beverages could affect our life style. The questionnaire was distributed to the subjects and the responses were collected. 


\section{RESULT}

In this survey questionnaire we came to know that $58 \%$ were aware about the harmful effects of beverages and the rest of $42 \%$ of them was not aware about this. This question was quite challenging and disgusting that Out of this $18 \%$ taking beverages daily and $67 \%$ of them taking beverages twice a day and $15 \%$ of them taking beverages occasionally (once in a week). $23 \%$ of them knows that intake of carbonated drinks leads to diabetes and rest of the $77 \%$ of them doesn't know about this. $17 \%$ of them knows that beverages causes osteoporosis and the rest $83 \%$ doesn't know that it will cause osteoporosis. Here $76 \%$ of them knows that beverages cause dental caries and dental erosion while $24 \%$ of them doesn't about this.33\% of them knows that beverages causes gum disease and while $67 \%$ doesn't know about it. $27 \%$ of them knows that beverages can cause sclerosis while $79 \%$ doesn't know about it. $41 \%$ knows that the chemical substance aspartame is used as substitutes for most of the beverages and the quite rest of them doesn't know about the chemical aspartame.

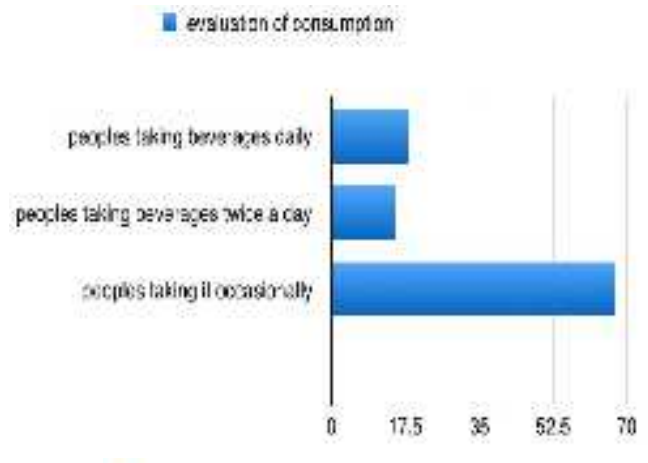

- awave abcut hantiul elfects of beveraces

Nol axiare

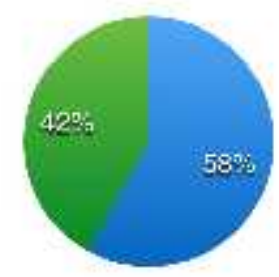

\section{DISCUSSION}

Over consumption of beverages is becoming serious and important health issues in today's lifestyle especially for youngsters and it should be essential for creating an awareness among the dental students about harmfulness of beverages.Gibson (2008) in his study showed that increased soft drink intake is related to lower consumption of milk and calcium, but average effect sizes were small. Soft drink consumption was also related to higher intake of carbohydrates, lower intakes of fruit and dietary fiber, and lower intakes of a variety of macronutrients in cross-sectional, longitudinal, and longer-term experimental studies. Interpreting the association between soft drink consumption and nutrient intake is complex [11]. Soft drink intake could be a marker for poor nutrition, with individuals who consume more sweetened beverages eating poorer diets in general. Soft drinks might also stimulate people's appetite for other nonnutritious food [13]. Bes-Rastrollo (Sanchez village) in his studyshowed that individuals who consumed more soft drinks consumed diets with higher overall glycemic indexes,] supporting the prediction that consumption of foods with high glycemic indexes (such as soft drinks) might stimulate intake of other such food.[4.] Trumbo PR, Rivers CR (2014) in his study showed that soft drink consumption is positively related to the consumption of foods such as hamburgers and pizza and negatively related to an overall healthy eating index[10]. The most striking finding, Guenther PM in his study of 249 women followed for 8 years, was that those who consumed 1 or more servings of soft drinks per day were at twice the risk of developing diabetes as those who consumed less than 1 serving per month [15]. In our studythere are about $69 \%$ who consumes beverages occasionally and risk of various diseases caused by consumption of beverages seems to be less for them.But at the same time about $18 \%$ of people says that they are aware that the beverages are harmful but still they are not able to restrain themselves from these habits.Several studies reported a positive association between soft drink consumption and health risks [ $\left[\begin{array}{llll}9 & 12 & 14 & 16\end{array}\right]$. Few studies highlighted the specific sources of health diseases related to soft drink consumption. The study indicates that the increased intake of beverages increases the health problems.Beverages are causing harmful effects but lot of students were unaware about this. So college personnel and parents should educate the collage students about the harmful effects of beverages. Awareness of harmfulness of beverages can be done by IEC Activities and through social media.

\section{CONCLUSION:}

From our study it is concluded thatbeverages are causing harmful effects but lot of students about $42 \%$ were unaware about this. So college personnel and parents should educate the collage students about the harmful effects of beverages. Awareness of harmfulness of beverages can be done by IEC Activities and through social media.

\section{Reference}

1. Rodriguez-Artalejo F, Garcia EL, Gorgojo L, et al. Consumption of bakery products, sweetened soft drinks and yogurt among children aged 6-7 years: association with nutrient intake and overall diet quality. Br J Nutr. 2003; 89:419-429. [PubMed]

2. Schulze MB, Manson JE, Ludwig DS, et al. Sugarsweetened beverages, weight gain, and incidence of type 2 diabetes in young and middle-aged women. JAMA. 2004; 292:927-934. [PubMed]

3. Stanton MF, Ahrens RA, Douglass LW. Coffee and cola beverage consumption as heart disease risk factors in men. Experientia. 1978; 34:1182-1183. [PubMed]

4. Guenther PM. Beverages in the diets of American teenagers. J Am Diet Assoc. 1986; 86:493-499. [PubMed]

5. Bes-Rastrollo M, Sanchez-Villegas A, Gomez-Gracia E, Martinez JA, Pajares RM, Martinez-Gonzalez MA. Predictors of weight gain in a Mediterranean cohort: the Seguimiento Universidad de Navarra Study 1. Am J Clin Nutr. 2006;83:362-370. [PubMed]

6. a b Cheney, Ralph (July 1947). "The Biology and Economics of the Beverage Industry". Economic Botany. 1 (3): 243-275. doi:10.1007/bf02858570. JSTOR 4251857. 
7. Jed Portman (2013-01-11). "Have You Ever Tried Hot Dr. Pepper? | Serious Eats: Drinks". Drinks.seriouseats.com. Retrieved 2013-05-08.

8. Mary Bellis (2009-03-06). "Joseph Priestley- Soda Water-Joseph Priestley". Inventors.about.com. Retrieved 2009-06-08.

9. a b c d e Vartanian LR, Schwartz MB, Brownell KD (2007). "Effects of soft drink consumption on nutrition and health: a systematic review and meta-analysis". American Journal of Public Health. 97 (4): 667-75. doi:10.2105/AJPH.2005.083782. PMC 1829363Freely accessible. PMID 17329656.

10. a b Gibson S (2008). "Sugar-sweetened soft drinks and obesity: a systematic review of the evidence from observational studies and interventions". Nutrition Research Reviews. 21 (2): 134-47. doi:10.1017/S0954 422408110976. PMID 19087367.

11. Trumbo PR, Rivers CR (2014). "Systematic review of the evidence for an association between sugarsweetened beverage consumption and risk of obesity". Nutrition Reviews. 72 (9): 566-74. doi:10.1111/nure. 12128. PMID 25091794.
12. David B. Samadi. "The sweeter side: Benefits and risks of artificial sweeteners". Fox New

13. Davy BM, Harrell K, Stewart J, King DS. Body weight status, dietary habits, and physical activity levels of middle school-aged children in rural Mississippi. South Med J. 2004; 97:571-577. [PubMed]

14. Harnack L, Stang J, Story M. Soft drink consumption among US children and adolescents: nutritional consequences. J Am Diet Assoc. 1999; 99:436-441. [PubMed]

15. Schulze MB, Manson JE, Ludwig DS, et al. Sugarsweetened beverages, weight gain, and incidence of type 2 diabetes in young and middle-aged women. JAMA. 2004; 292:927-934. [PubMed]

16. Guenther PM. Beverages in the diets of American teenagers. $J$ Am Diet Assoc. 1986; 86:493-499. [PubMed]

17. Bowman SA. Beverage choices of young females: changes and impact on nutrient intakes. J Am Diet Assoc. 2002; 102:1234-1239. [PubMed]

18. De Castro JM. The effects of the spontaneous ingestion of particular foods or beverages on the meal pattern and overall nutrient intake of humans. Physiol Behav. 1993; 53:1133-1144. [PubMed]

19. DiMeglio DP, Mattes RD. Liquid versus solid carbohydrate: effects on food intake and body weight. Int J Obes Relat Metab Disord. 2000; 24:794-800. [PubMed]

\section{How to cite this article:}

Mugilan MR and Preetha S (2017) 'Awareness Amongst Dental Students About The Harmful Effects Of Beverages', International Journal of Current Advanced Research, 06(03), pp. 2904-2906.

DOI: http://dx.doi.org/10.24327/ijcar.2017.2906.0138 